RESEARCH

\title{
MADD silencing enhances anti-tumor activity of TRAIL in anaplastic thyroid cancer
}

\author{
Shikha Saini', Lakshmi Sripada1, Kiara Tulla², Guilin Qiao², Nicholas Kunda², Ajay V Maker,2 \\ and Bellur S Prabhakar1,3
}

'Department of Microbiology and Immunology, University of Illinois College of Medicine, Chicago, Illinois, USA 2Department of Surgery, University of Illinois College of Medicine, Chicago, Illinois, USA

3jesse Brown VA Medical Centre, Chicago, Illinois, USA

Correspondence should be addressed to B S Prabhakar: bprabhak@uic.edu

\begin{abstract}
ATC is an aggressive disease with limited therapeutic options due to drug resistance. TRAIL is an attractive anti-cancer therapy that can trigger apoptosis in a cancer cellselective manner. However, TRAIL resistance is a major clinical obstacle for its use as a therapeutic drug. Previously, we demonstrated that MADD is a cancer cell pro-survival factor that can modulate TRAIL resistance. However, its role, if any, in overcoming TRAIL resistance in ATC is unknown. First, we characterized ATC cell lines as either TRAIL resistant, TRAIL sensitive or moderately TRAIL sensitive and evaluated MADD expression/ cellular localization. We determined the effect of MADD siRNA on cellular growth and investigated its effect on TRAIL treatment. We assessed the effect of combination treatment (MADD siRNA and TRAIL) on mitochondrial membrane potential (MMP) and reactive oxygen species (ROS) levels. The effect of combination treatment on tumor growth was assessed in vivo. We found increased levels of MADD in ATC cells relative to Nthy-ori 3-1. MADD protein localizes in the cytosol (endoplasmic reticulum and Golgi body) and membrane. MADD knockdown resulted in spontaneous cell death that was synergistically enhanced when combined with TRAIL treatment in otherwise resistant ATC cells. Combination treatment resulted in a significant reduction in MMP and enhanced generation of ROS indicating the putative mechanism of action. In an orthotopic mouse model of TRAIL-resistant ATC, treatment with MADD siRNA alone reduced tumor growth that, when combined with TRAIL, resulted in significant tumor regressions. We demonstrated the potential clinical utility of MADD knockdown in sensitizing cells to TRAIL-induced apoptosis in ATC.
\end{abstract}

\section{Introduction}

Anaplastic thyroid cancer (ATC) is a rare subtype of thyroid cancer; however, it accounts for a significant proportion of thyroid cancer-related mortality (Roche et al. 2018). ATCs are extremely aggressive, with a near 100\% diseasespecific mortality and a median survival of 3-5 months (Kunstman et al. 2015). Due to its dedifferentiated histology,
ATC is resistant to standard radioiodine ablation and hormone suppression therapies. Treatment relies on aggressive surgery and external-beam radiation combined with chemotherapy and/or multi-kinase inhibitors. The majority of patients present with symptomatic, locally advanced disease invading surrounding tissues or (c) 2019 Society for Endocrinology Published by Bioscientifica Ltd. Printed in Great Britain 
with metastases, which compounds the relative ineffectiveness of current therapies. Though significant research has been conducted to discover novel molecular targets, unfortunately, effective treatments remain limited.

TRAIL (tumor necrosis factor-related apoptosisinducing ligand) is considered an effective anti-cancer drug due to its ability to induce apoptosis in a cancer cell-specific manner by engaging death receptors (DR4 and DR5). Upon binding to DRs, it causes formation of death-inducing signaling complex (DISC) consisting of Fas-associated death domain-containing protein (FADD) and pro-caspase-8. Subsequently, it leads to proximity-induced activation of caspase -8 and then caspase-3 (Li et al. 2010, Shirley et al. 2011). Due to native or acquired TRAIL resistance in some aggressive cancers, its clinical utility is yet to be fully established. The molecular mechanisms underlying TRAIL resistance include (1) differential expression of death receptors; (2) increased expression levels of anti-apoptotic molecules such as FLIP, XIAPs and Bcl-2-family proteins; and (3) hyperactivation of AKT and NF- $\kappa$ B signaling (Mahalingam et al. 2009). Overcoming TRAIL resistance can enhance its therapeutic utility (Prabhakar et al. 2008).

Earlier we showed that MAPK-associated death domain-containing protein (MADD) is selectively expressed in cancer cells and it plays a critical role in TRAIL resistance in different cancers (Al-Zoubi et al. 2001, Efimova et al. 2004, Ramaswamy et al. 2004, Mulherkar et al. 2006, Prabhakar et al. 2008, Subramanian et al. 2009, Li et al. 2010, 2011, 2013, Turner et al. 2013, Carr et al. 2016). MADD is an Akt substrate and undergoes Akt-mediated phosphorylation at three different sites. Upon Akt phosphorylation, MADD binds to DR4 and prevents FADD recruitment, and thereby contributes to TRAIL resistance (Ramaswamy et al. 2004, Mulherkar et al. 2007, Li et al. 2010, 2011). In TRAIL-sensitive cells, TRAIL can enhance PTEN activity resulting in decreased levels of pMADD. When MADD is not phosphorylated by Akt, it cannot bind to DRs and thus allow FADD recruitment leading to DISC formation and eventual cell death. Thus, pMADD plays a pro-survival role in TRAIL signaling and targeting MADD can restore and enhance TRAIL sensitivity even in TRAIL-resistant cells (Prabhakar et al. 2008, Carr et al. 2011, 2016, Turner et al. 2013). Earlier, we have reported the pro-survival role of MADD in differentiated thyroid cancers such papillary and follicular thyroid cancers, which can be readily treated with excellent outcomes (Subramanian et al. 2009, Li et al. 2013). Unlike for differentiated thyroid cancers, there is no effective treatment for ATC (Roche et al. 2018), which is highly aggressive and therapeutically most challenging among all thyroid cancers. Therefore, in this study, we set out to systemically investigate the synergy, if any, between MADD silencing and TRAIL treatment. Additionally, we tested the translational applicability of the combined treatment strategy in vivo in an orthotopic xenograft mouse model. This is the first study providing the proof of principle to explore the potential utility of combining MADD siRNA with TRAIL for treating ATC.

\section{Materials and methods}

\section{Cell culture and mice maintenance}

Eight ATC cell lines (8305C, 8505C, C643, HTH7, CAL62, MB1, BHT101, SW1736) were procured from ATCC (Manassas, VA, USA), University of Colorado Cancer Center (Denver, CO, USA) or Deutsche Sammlung von Mikroorganismen und Zellkulturen (Braunschweig, Germany). Cells were tested for authenticity and mycoplasma contamination (Idexx Laboratories Inc., Westbrook, MN, USA). Cells were cultured in their recommended media supplemented with 10\% FBS and $1 \mathrm{x}$ antibiotic (GIBCO) and maintained in a humidified $\mathrm{CO}_{2}$ incubator at $37^{\circ} \mathrm{C}$.

Athymic nude mice (Charles River Laboratories) were kept in the Biological Resource Laboratory (BRL facility) at the University of Illinois at Chicago (Chicago, IL, USA), in hygienic conditions. All animal experiments were approved and performed in accordance with the guidelines set forth by the Animal Care and Use Committee at the University of Illinois at Chicago and Jesse Brown VA Medical Center (Chicago, IL, USA). Mice were fed a normal diet and routinely monitored for optimal health.

\section{TRAIL susceptibility determination}

TRAIL-induced apoptosis was measured by active caspase-3 staining in ATC cells. Briefly, cells were treated with different concentrations of TRAIL (3.125-100 ng/mL) for $6 \mathrm{~h}$ and processed for caspase- 3 staining using PE active caspase-3 apoptosis kit (BD Pharmingen, San Jose, CA, USA), as per manufacturer's protocol. Cells were analyzed using CyAn 1 bench-top flow cytometer and the Summit software was used to determine percent apoptosis.

\section{qRT-PCR and Western blotting}

MADD mRNA expression was quantified using MADDspecific primers (MADD forward: 5'-GCCAGCAGCCTCTAT CGG-3', MADD reverse: 5'-GCCCAAATACTTTCAGAC-3',
C) 2019 Society for Endocrinology Published by Bioscientifica Ltd. Printed in Great Britain 
GAPDH forward: 5'-TGTGGGCATCAATGGATTTGG-3' and GAPDH reverse: 5'-ACACCATGTATTCCGGGTCAAT-3'. $G A P D H$ was used to normalize the target gene expression. Briefly, total RNA was isolated from the cells by Rneasy Mini Kit (Qiagen). One microgram total RNA was used to synthesize cDNA using iScript cDNA Synthesis Kit (Bio-Rad), followed by PCR using SYBR Green Supermix (Bio-Rad), respectively. As a baseline, cDNA derived from a normal thyroid-derived cell line, Nthy-ori 3-1 was used (Sigma Aldrich). Samples were run and analyzed in Bio-Rad CFX Connect Real-time System. For Western blotting, cells were harvested and lysed with RIPA buffer (1MEDTA, $1 \mathrm{mMNa} 3 \mathrm{VO} 4,1 \mathrm{mMNaF}, 50 \mathrm{mM}$ Tris-HCl, pH 7.4, $150 \mathrm{mM} \mathrm{NaCl}, 1 \% \mathrm{NP}-40,0.25 \%$ sodium deoxycholic acid) containing protease and phosphatase inhibitor cocktail (Sigma Aldrich). The protein supernatant was quantified using Pierce $660 \mathrm{~nm}$ protein assay reagent (ThermoFisher Scientific). Western blotting was carried out as described earlier (Ramaswamy et al. 2004, Qiao et al. 2017). Relative densities were quantified using Image J2 software.

\section{Cellular localization studies}

Cytosolic and membrane localization of MADD was determined by immunofluorescence (IF) assay and flow cytometry, respectively. For IF, cells were allowed to grow on coverslips to attain 70-80\% confluency and fixed with $4 \%$ paraformaldehyde ( $\mathrm{pH} 7.4$ ) for $10 \mathrm{~min}$ at $4^{\circ} \mathrm{C}$. After that, cells were permeabilized with $0.5 \%$ Igepal (Sigma Aldrich), washed with TBST (0.1\% Tween 20 in TBS) and blocked with 5\% BSA solution. Cells were incubated with the anti-MADD antibody (1:100) (Sigma Aldrich) overnight at $4^{\circ} \mathrm{C}$, washed with TBST and again, incubated with antirabbit FITC (1:200) antibody. For colocalization studies, we sequentially probed the cells with anti-calreticulin antibody (Abcam) and anti-giantin antibody (Abcam) for endoplasmic reticulum (ER) and Golgi body staining, respectively, followed by treatment with Cy3-conjugated secondary antibody (Jackson ImmunoResearch). After washing, cellular nuclei were stained with DAPI solution and coverslips were placed on to the slide using mounting medium (ThermoFisher Scientific). Microphotographs were captured using a Keyence microscope at 600x magnification. Colocalization was assessed by calculating Mander's coefficient using Image J2 software (Coloc2 Plugin). Mander's coefficient is based on pixel-to-pixel overlap between two different fluorophores and ranges from 0 to 1 , where $0=$ no overlap and $1=$ complete overlap, as defined earlier (Purdy et al. 2014). For membrane localization analysis, cells were harvested, fixed and stained with anti-MADD antibody for overnight at $4^{\circ} \mathrm{C}$. Cells were washed and incubated with FITCconjugated anti-rabbit secondary antibody for an hour at RT. Cells were washed and subjected to flow-cytometric analysis, as described earlier (Qiao et al. 2017). Cells stained with only secondary antibody were used as a baseline control for MADD expression analysis.

\section{SiRNA titration studies}

For in vitro transfections, different concentrations of MADD siRNA were titrated to determine the optimum dose at which maximum cell death can be obtained. Scramble siRNA (scrambled MADD siRNA sequence) was used as a control. The siRNA sequence used are MADD gene (Exon 13L) targeting siRNA ((sense strand: 5'-CGGCGAAUCUAUGACAAUCTT-3') (antisense strand: 5'-GAUUGUCAUAGAUUCGCCGTT-3')) and scramble siRNA ((sense strand: 5'-UUGCUAAGCGUCGGUCAA UTT-3') (antisense strand: 5'-AUUGACCGACGCUUAGCA ATT-3')). We selected this particular siRNA as this had been thoroughly characterized in terms of efficacy, specificity and sensitivity in our previous studies (Mulherkar et al. 2006, 2007, Li et al. 2011). All transfections were performed using RNAimax reagent (ThermoFisher Scientific), as per manufacturer's instructions.

\section{Cytotoxicity and synergism analysis}

The number of viable cells was quantified by a colorimetric assay using 3-(4,5-dimethylthiazol-2-yl)-2,5-diphenyltetrazolium bromide (MTT; $10 \mu \mathrm{L}$ of $5 \mathrm{mgm} / \mathrm{L}$ solution), which was added to each well of the titration plate and incubated for $2 \mathrm{~h}$ at $37^{\circ} \mathrm{C}$. Dimethyl sulfoxide $(40 \mu \mathrm{L} /$ well) was added to solubilize the formazan crystals, followed by incubation for $60 \mathrm{~min}$ at $37^{\circ} \mathrm{C}$. The absorbance was recorded at an activation wavelength of $570 \mathrm{~nm}$ and a reference wavelength of $630 \mathrm{~nm}$. Combination Index was determined using Chou-Talalay equations-based software (Chou 2010) and graphs were plotted in GraphPad Prism using CI values obtained by using the algorithm in CompuSyn software (ComboSyn, Paramus, NJ, USA). We categorized $\mathrm{CI}<0.7$ as synergism, $\mathrm{CI}=0.7-1.3$ as an additive effect and $\mathrm{CI}>1.3$ as antagonism, as described earlier (Luszczki et al. 2003).

\section{MMP quantification}

Mitochondrial activity was measured by using JC-1 dye (ThermoFisher Scientific). At higher potential, JC-1 dye 
forms aggregates in energized mitochondria and emits red fluorescence. In contrast, in depolarized mitochondria, it exists as monomers and emits green fluorescence. The ratiometric value of red/green fluorescence directly correlates with mitochondrial health. After $48 \mathrm{~h}$ of transfection, cells were stained with a JC- 1 dye $(5 \mu \mathrm{M})$ for $30 \mathrm{~min}$. Absorbance was recorded at $530 \mathrm{~nm}$ and $590 \mathrm{~nm}$ by using Synergy 2 multimode plate reader (BioTek Instruments, Inc) and the ratiometric values were calculated.

\section{ROS generation}

Cellular oxidative stress was assessed using the ROS-sensitive DCFDA (2,7-dichlorodihydrofluorescein diacetate) fluorescent probe as previously described (Jung et al. 2005). DCFDA is a cell permeable dye, which forms fluorescent $2^{\prime}, 7^{\prime}$-dichlorofluorescein (DCF) when cleaved by non-specific esterases and oxidized by peroxides in cells. Briefly, $0.2 \times 10^{6}$ cells were plated in a six-well plate and allowed to attach overnight. After $48 \mathrm{~h}$ of transfection, cells were treated with TRAIL $(100 \mathrm{ng} / \mathrm{mL})$ for $6 \mathrm{~h}$ at $37^{\circ} \mathrm{C}$. After treatment, cells were incubated with $5 \mu \mathrm{M}$ DCFDA at $37^{\circ} \mathrm{C}$ for $15 \mathrm{~min}$. Subsequently, cells were washed with PBS, microphotographed using Keyence microscope in the green channel.

\section{Orthotopic tumor experiment}

For assessing the therapeutic efficacy of MADD siRNA and combination treatment (MADD siRNA and TRAIL, henceforth), we used a TRAIL-resistant cell line, 8505C to generate tumors in athymic nude mice. In brief, under our ACCC-approved protocol, animals were anesthetized, and a midline neck incision was made. Strap muscles were retracted laterally to expose the thyroid gland. Under $2.5 \times$ magnification, a $50 \mu \mathrm{L}$ Hamilton syringe with a $30 \mathrm{~g}$ needle was utilized to introduce $0.5 \times 10^{6}$ cells directly into the left thyroid lobe. Successful technique and animal survival were $98 \%$ on day 0 . Mice were routinely monitored for their optimal health. When tumors attained the volume of $50-60 \mathrm{~mm}^{3}$ after 3-4 weeks, mice were randomized into six groups before initiating treatment. Treatment-based groups were saline control, scramble siRNA, MADD siRNA, saline+TRAIL, scramble siRNA+TRAIL and MADD siRNA+TRAIL. Mice were given a total of five doses of treatment on day 34,36, 38, 40 and 42. Treatment regimen entailed five intra-tumoral doses of injectable saline $(50 \mu \mathrm{L}$ per dose) or MADD/scramble siRNA $(4 \mathrm{mg} / \mathrm{kg})$ prepared in Invivofectamine Reagent (ThermoFisher Scientific) on every alternate day.
TRAIL was administered intraperitoneally (500 $\mu \mathrm{g} / \mathrm{dose})$ on the siRNA treatment day. Tumors were measured daily, and volume was calculated using the formula: $\mathrm{V}=1 / 2 \times 1 \times \mathrm{b}^{2}$, where 1 is the largest diameter of tumor and $\mathrm{b}$ is the perpendicular diameter. Treatment responses were assessed by WHO ( $\geq 50 \%$ decrease in the greatest perpendicular tumor diameters) and RECIST ( $\geq 30 \%$ decrease in the maximum tumor diameter) criteria. At the end of the experiment (day 43), mice were killed and tumors were resected, fixed and sectioned. Activation of apoptosis in tumors was determined by performing immunohistochemical staining for activated caspases-8 and 9, as described previously (Saini et al. 2013). IHC staining assessment was performed using Image J software using the manual cell counter plugin. We considered dark brown-stained cells as positive cells and counted 500 cells from five different fields. Average of positively stained cells is represented as percentage immunoreactivity.

\section{Statistical analysis}

We used a two-tailed unpaired Student's t-test or a Mann-Whitney $U$-test to determine the significant difference between groups. A $P$ value less than 0.05 was considered statistically significant.

\section{Results}

\section{ATC cells exhibit differential TRAIL sensitivity irrespective of MADD expression levels}

We first determined TRAIL susceptibility by measuring TRAIL-induced apoptosis at different concentrations for $6 \mathrm{~h}$ in all cell lines. We measured apoptosis by probing for active caspase-3, followed by flow-cytometric analysis. The data showed that these ATC cell lines varied in their TRAIL sensitivities and could be broadly classified as TRAIL sensitive (50-100\%), moderately TRAIL sensitive (30-50\%) and TRAIL resistant (0-30\%) depending on the percent of apoptosis induced. As such, BHT101, MB1 and HTH7 cells were TRAIL sensitive, C643 and 8305C cells were moderately TRAIL sensitive and CAL62, 8505C and SW1736 cells were TRAIL resistant (Fig. 1A).

Our qRT-PCR analysis showed that as compared to the Nthy-ori 3-1 normal thyroid cells, all ATC cells had significantly higher normalized MADD transcript expression indicating that MADD can be targeted with minimal effect on healthy cells $(P<0.005$; Fig. 1B). GAPDH was amplified and used to normalize the target gene 


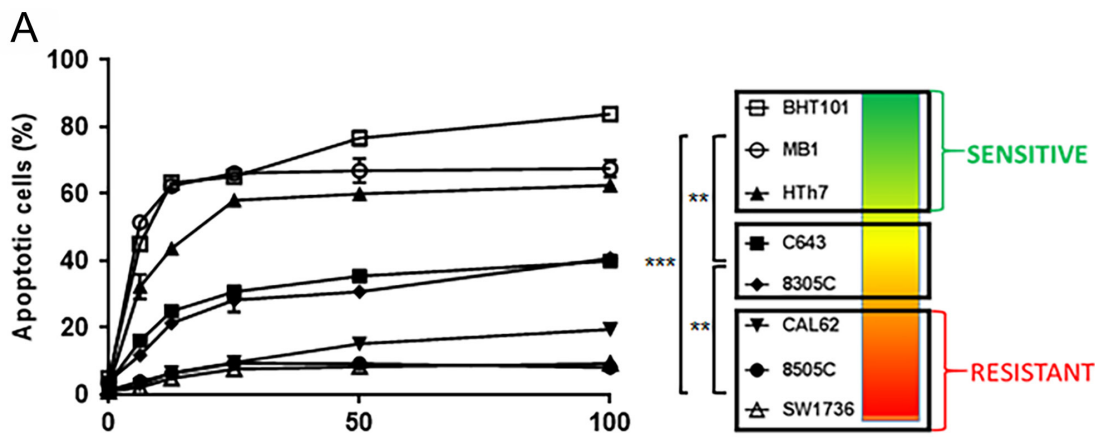

TRAIL concentration ( $\mathrm{ng} / \mathrm{ml})$

B

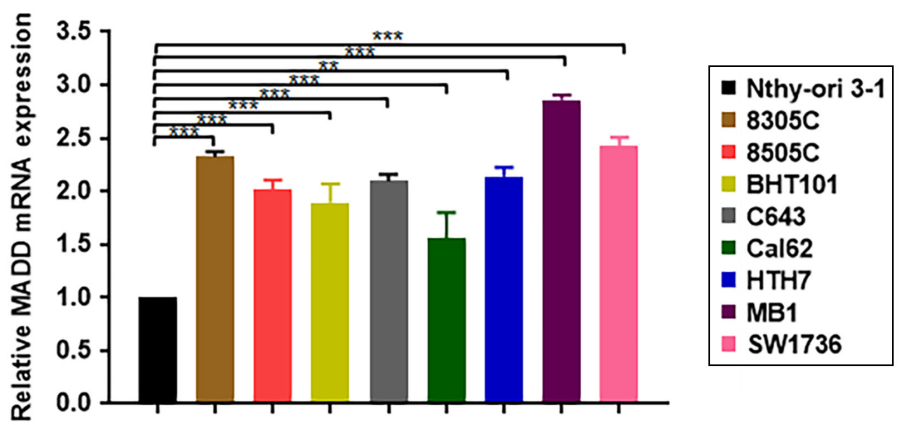

C

MADD

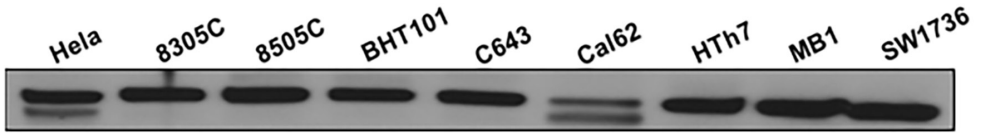

$\beta$-actin

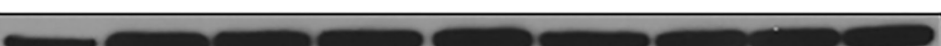

\section{Figure 1}

TRAIL sensitivity and MADD expression in different ATC cell lines: (A) Cells were treated with varying concentrations of TRAIL and stained for active caspase- 3 expression to determine the percentage of apoptotic cells. Cells were categorized as TRAIL sensitive (BHT101, MB1 and HTH7), moderately TRAIL sensitive (C643 and 8305C) and TRAIL resistant (CAL62, 8505C and SW17326) according to the levels of TRAILinduced apoptosis. (B) MADD expression was quantified in all ATC cell lines by qRT-PCR, with $G A P D H$ as an internal loading control. A normal human thyroid-derived cell line, Nthy-ori 3-1, was used as a baseline control. (C) MADD protein levels were further validated by Western blotting in all cell lines. HeLa cells were used as a positive control. All experiments were performed in triplicates and repeated. Significance is represented as $*(P<0.05), * *(P<0.005)$, $\star \star \star(P<0.0005)$. expression. We further validated MADD protein levels in all ATC cells by Western blotting and confirmed that MADD protein is expressed in all ATC cells (Fig. 1C) and at a higher level in ATC cells (8505C, C643 and HTH7) relative to the level of expression seen in Nthy-ori 3-1 cells (Supplementary Fig. S1, see section on supplementary data given at the end of this article). As we previously established, high MADD protein levels are present in Hela cells (Kurada et al. 2009); therefore, we used it as a positive control. No statistically significant association was observed between TRAIL sensitivity and MADD mRNA expression, as depicted by Pearson's chi-square test $(P=0.885)$. For all subsequent experiments, we chose one representative cell line from each group: 8505C (TRAIL resistant), C643 (moderately TRAIL sensitive) and HTH7 (TRAIL sensitive).

\section{MADD protein localizes in the cytosol, membrane, ER and Golgi body of ATC cells}

We characterized MADD protein distribution in ATC cells by performing immunofluorescence (IF) microscopy (for cytosolic localization) and flow cytometry (for membrane localization). Our IF studies in fixed and permeabilized cells showed the presence of abundant MADD protein primarily in the cytosol, with little or no expression in the nucleus of 8505C, C643 and HTH7 cells (Fig. 2A). Further, MADD protein was also detected in the cellular membrane by an IF-based assay. To discriminate if these results were due to non-specific binding of the antibody to the permeabilized membrane, we validated the membrane localization of MADD by flow cytometry. Our analysis revealed that MADD protein is localized on the cellular surface of $8505 \mathrm{C}(99.8 \pm 2.98 \%)$, C643 (99.5 $\pm 2.95 \%)$ and HTH7 cells $(98.3 \pm 2.67 \%$ ) (Fig. 2B). Our IF studies were suggestive of perinuclear localization of MADD protein. To further resolve its localization, we performed colocalization studies with ER marker (calreticulin) and Golgi body marker (giantin), which revealed that MADD localizes in the ER as well as in the Golgi body (Fig. 2C and D).

\section{MADD siRNA treatment induces spontaneous ATC cell death}

In the next series of experiments, we targeted MADD by using RNA interference-based approach. First, we carried out siRNA titration studies after $48 \mathrm{~h}$ of transfection 
B

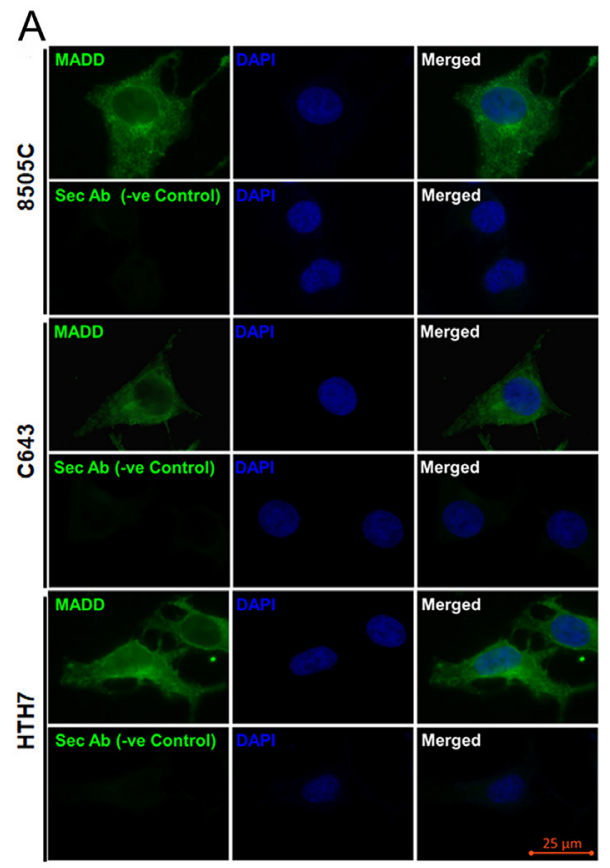

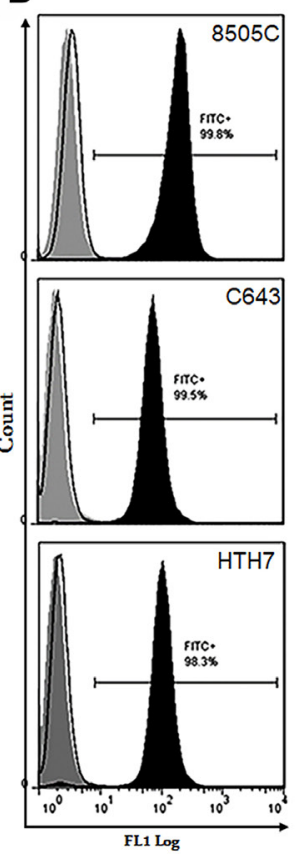

C

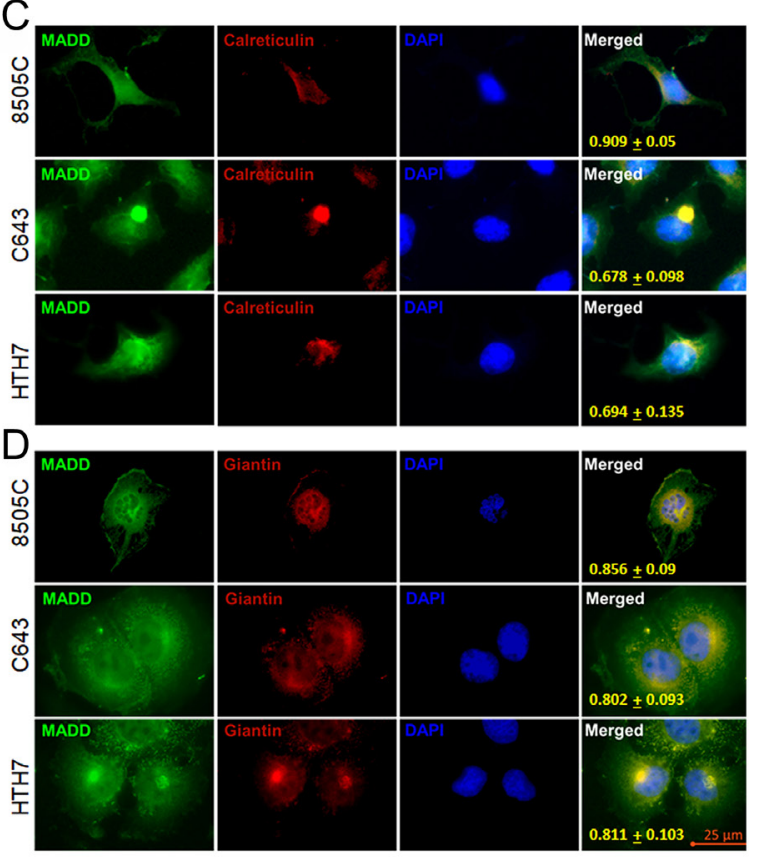

Figure 2

Cellular localization of MADD protein in ATC cells: (A) Representative microscopic images of 8505C, C643 and HTH7 cells, showing MADD protein's cytosolic localization by fluorescence microscopy. MADD protein was probed with a FITC-conjugated secondary antibody (green fluorescence). DAPI (blue color) depicts nuclear staining. (B) Overlay histogram showing membrane localization of MADD protein in 8505C, C643 and HTH7 cells. Gray histogram represents untreated control cells; white histogram shows secondary antibody-stained control cells, and black histogram encodes anti-MADD antibodystained cells. ( $C$ and D) Representative images showing co-staining of MADD with calreticulin and giantin, respectively. Colocalization was quantified by assessing Mander's coefficient, represented on merged images. (Magnification 600x; Objective 60×).

using an MTT assay to determine whether MADD siRNA treatment could inhibit cellular growth. We found that $10 \mathrm{nM}$ MADD siRNA was the optimum silencing dose for all three cell lines, thus reducing non-specific and adverse effects of siRNA treatment (Fig. 3A). Transfection with $10 \mathrm{nM}$ MADD siRNA resulted in significant reduction in the growth in $8505 \mathrm{C}(36.1 \pm 4.36 \%), \mathrm{C} 647$ (34.4 $44.37 \%)$ and HTH7 $(40.3 \pm 3.055 \%)$ cells $(P<0.001)$. Next, we validated whether MADD siRNA-mediated cytotoxicity is concomitant with MADD protein ablation by Western blotting. As shown in Fig. 3B, there was approximately $60-70 \%$ reduction in MADD protein levels in all three cell lines after 48 and $72 \mathrm{~h}$ of transfection, in comparison to the vehicle (RNAimax reagent alone) and scramble siRNAtransfected cells. $\beta$-actin was used as an internal loading control. Overall, our titration studies showed that MADDspecific siRNA was capable of depleting MADD protein and could significantly induce specific cytotoxicity in ATC cells.

\section{MADD siRNA treatment enhances TRAIL activity}

As MADD phosphorylation contributes to TRAIL resistance in cancer cells, we hypothesized that MADD silencing could restore TRAIL sensitivity and the combination treatment could have improved anti-tumor effects. To explore the pharmacological relevance of the combination treatment, we examined the correlation between MADD siRNA and TRAIL by using Chou-Talalay method based algorithm to calculate combination index. Cellular toxicity assessed by MTT assay was used as the fraction affect to assess the correlation between MADD siRNA and TRAIL. Combination treatment induced significantly higher cytotoxicity in 8505C, C643 and HTH7 cells, as compared to TRAIL alone and/or MADD siRNA alone (Fig. 4A, $\mathrm{B}$ and $\mathrm{C}$ ). In $8505 \mathrm{C}$ cells, synergism with MADD siRNA was observed at most of the TRAIL concentrations with corresponding CI of 0.63375 at $6.25 \mathrm{ng} / \mathrm{mL}, 0.54564$ at $12.5 \mathrm{ng} / \mathrm{mL}, 0.48291$ at $25 \mathrm{ng} / \mathrm{mL}$ and 0.46978 at $50 \mathrm{ng} / \mathrm{mL}$. C643 cells exhibited an additive effect at all TRAIL concentrations (CI: 0.7-1.3). As anticipated, due to high fraction affect, we did not observe the synergism in C643 cells (moderately TRAIL sensitive) at the given TRAIL concentration range. Similarly, HTH7 cells demonstrated the additive effect at lower TRAIL concentrations (CI: 0.98174 at $3.125 \mathrm{ng} / \mathrm{mL}$; CI: 0.70538 at $60.25 \mathrm{ng} / \mathrm{mL}$ ) and a synergistic effect at higher TRAIL concentrations
(C) 2019 Society for Endocrinology Published by Bioscientifica Ltd. Printed in Great Britain 


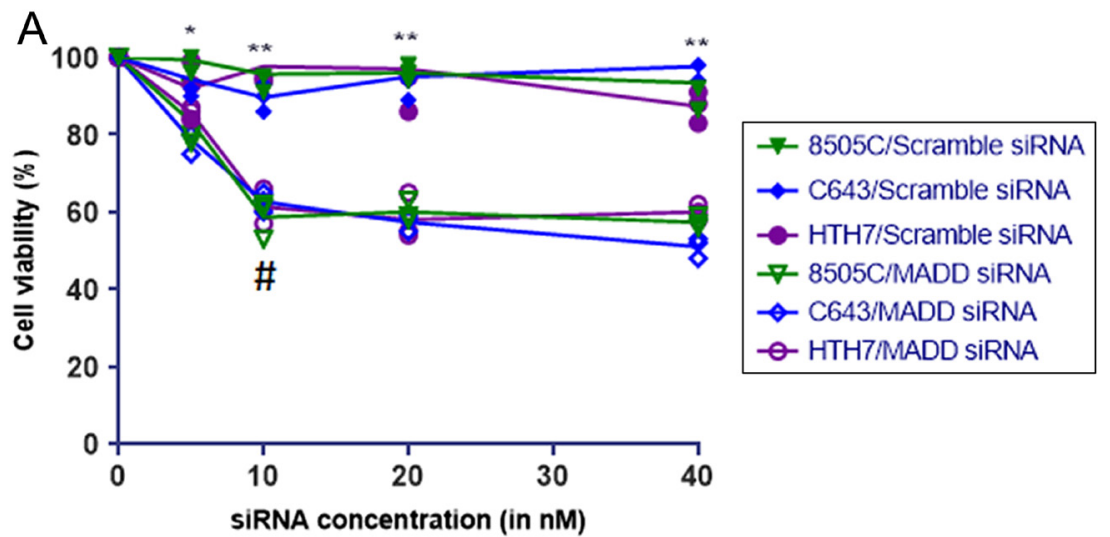
Figure 3
MADD siRNA's effect on cellular growth and MADD expression: (A) siRNA titration studies were performed after $48 \mathrm{~h}$ of transfection using different concentrations. $10 \mathrm{nM}$ MADD siRNA was effective in reducing cellular growth in all ATC cells when compared to the scramble siRNA, without any transfection-related toxicity. (B) Western blotting showing the efficacy of MADD siRNA (10 nM) to knockdown MADD protein levels at 48 and $72 \mathrm{~h}$. \# denotes the effective siRNA dose for MADD knockdown. Significance is represented as $*(P<0.05)$, $\star *(P<0.005), * \star *(P<0.0005)$. A full colour version of this figure is available at https://doi. org/10.1530/ERC-18-0517.

B

$8505 C$
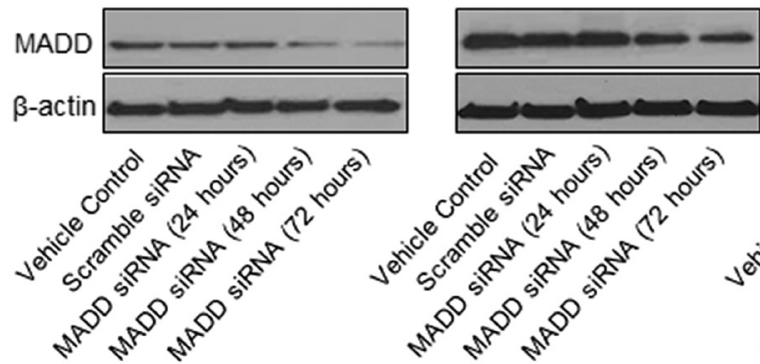

C643
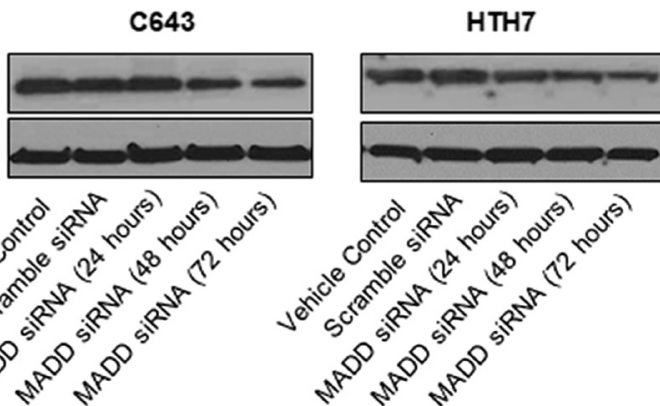

$(0.66038$ at $12.5 \mathrm{ng} / \mathrm{mL}, \quad 0.66591$ at $25 \mathrm{ng} / \mathrm{mL}$ and 0.50590 at $50 \mathrm{ng} / \mathrm{mL}$ ). Based on these findings, it appears that treatment with MADD siRNA can synergize with TRAIL-induced cell death in TRAIL-resistant cells and exhibits an additive effect in moderately TRAIL-sensitive and TRAIL-sensitive cells.

\section{Apoptosis accounts for the majority of combination treatment-mediated cytotoxicity}

We next characterized the molecular phenotype of combination treatment-induced cytotoxicity. To accomplish this, we used active caspase-3 staining-based flow cytometry assay and found that combination treatment-induced cell death was largely due to apoptosis. As shown in Fig. 4D, in comparison to the vehicle control $(5.6 \pm 0.86 \%)$ and scramble siRNA-transfected cells $(8.76 \pm 2.13 \%)$, MADD siRNA-transfected TRAIL-resistant, 8505 C cells $(38.7 \pm 2.56 \%)$ had a higher percentage of apoptotic cells $(P<0.0001$; $P<0.0001)$. Additionally, treatment with TRAIL caused significantly higher apoptosis in $8505 \mathrm{C}$ cells transfected with MADD siRNA $(59.9 \pm 3.49 \%)$, as compared to vehicle control $(12.3 \pm 2.36 \%)$ and scramble siRNA $(16.78 \pm 3.46 \%)$ $(P<0.0001 ; P<0.0001)$.

In moderately TRAIL-sensitive C643 cells, MADD siRNA-transfected cells $(42.1 \pm 2.13 \%)$ also had a higher percentage of apoptotic cells, in contrast to vehicle control $(6.9 \pm 0.97 \%)$ and scramble siRNA-transfected cells $(11.2 \pm 3.1 \%) \quad(P<0.0001 ; P<0.0001)$. While TRAIL had a modest effect on vehicle control $(34.7 \pm 2.89 \%)$ and scramble siRNA-transfected cells $(42.1 \pm 3.45 \%)$, it had a more significant effect on MADD siRNA-transfected cells $(62.7 \pm 4.59 \%)(P=0.0009 ; P=0.0034)$ (Fig. 4E).

Similarly, in TRAIL-sensitive HTH7 cells, it was observed that MADD-depleted cells $(44.3 \pm 1.46 \%)$ had significantly increased cell death versus vehicle control $(8.9 \pm 1.21 \%)$ and scramble siRNA-transfected cells $(11.5 \pm 2.74 \%) \quad(P<0.0001 ; P<0.0001)$. TRAIL treatment caused increased cell death in vehicle control $(62.7 \pm 3.46 \%)$ and scramble siRNA-transfected cells (69.4 $\pm 3.11 \%)$, with a further significant increase in MADD siRNA-transfected cells $(83.5 \pm 3.94 \%)(P=0.0024 ; P=0.0082)$ (Fig. 4F).

\section{Combination treatment with MADD siRNA and TRAIL reduces MMP}

We further determined the effect of combination treatment on mitochondrial membrane depolarization using JC-1 staining, which forms aggregates emitting red fluorescence inside the mitochondria depending upon the mitochondrial potential. When the mitochondrial membrane is depolarized, it remains in the monomeric form, characterized by green fluorescence. JC-1 aggregate/monomer ratio is directly related to the number of polarized mitochondria in the cell population. Our fluorimetry-based ratiometric results indicated that 
A
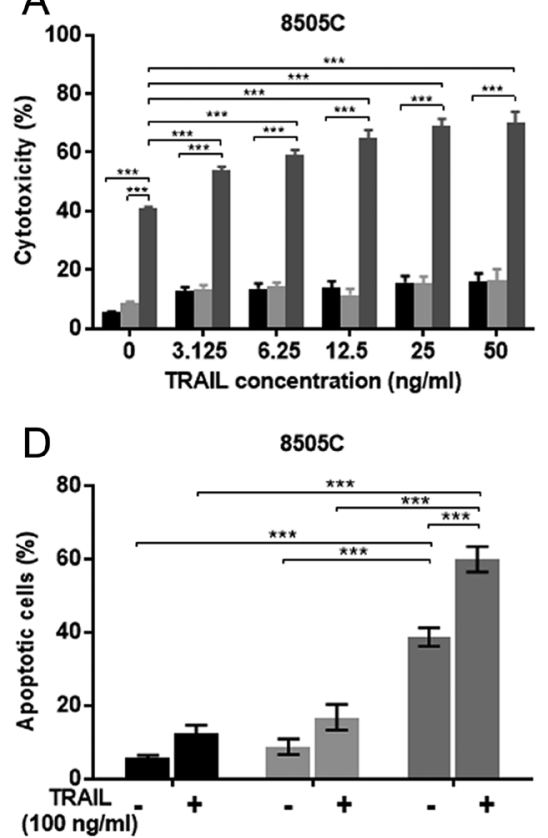

B

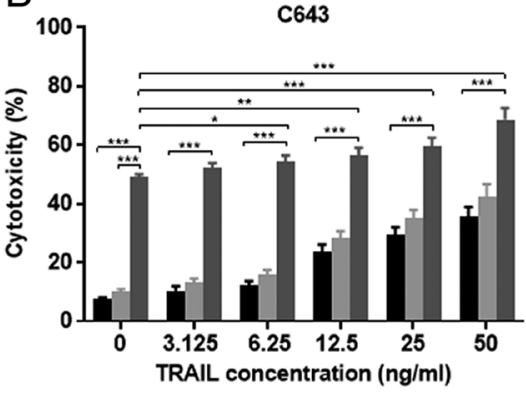

E

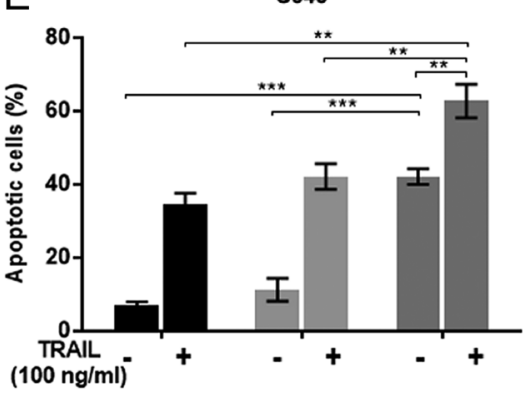

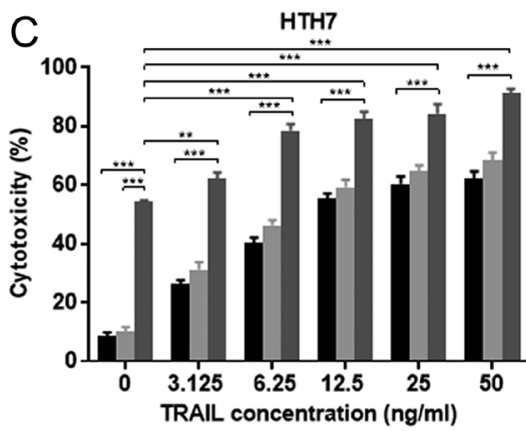

F

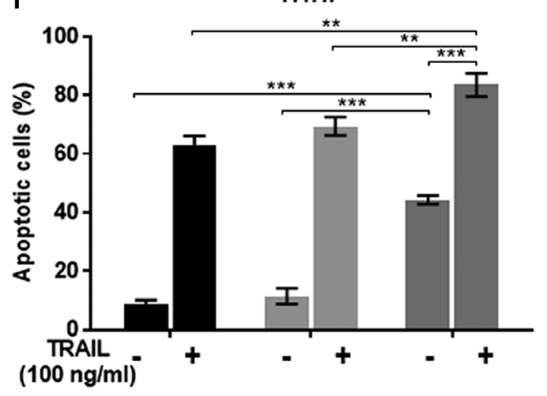

Vehicle Control Scramble siRNA MADD siRNA

\section{Figure 4}

MADD siRNA enhances TRAIL cytotoxicity in vitro: (A, B, C) TRAIL treatment of cells pre-transfected with 10 nM MADD siRNA showed significantly increased cytotoxicity as compared to those transfected with vehicle only and scramble siRNA. (D, E, F) Apoptosis constitutes the majority of combination treatment-induced cytotoxicity: Bar graphs showing the percentage of apoptosis (active caspase-3 positively stained cells) upon TRAIL treatment, in cells pre-transfected with vehicle control, scramble siRNA and MADD siRNA. Data are represented as mean \pm s.D. Significance is represented as * $(P<0.05)$, $\star *(P<0.005), * * \star(P<0.0005)$.

MADD siRNA treatment could significantly reduce the MMP in ATC cells, as compared to vehicle control and scramble siRNA treated $8505 \mathrm{C}$ cells $(P=0.0003 ; P=0.0015)$ (Fig. 5A). Similar results were observed in C643 $(P<0.0001$; $P<0.0001)$ and HTH7 $(P<0.0001 ; P<0.0001)$ cells. However, additional TRAIL treatment considerably lowered the MMP in MADD siRNA-transfected cells as compared to vehicle control and scramble siRNA-transfected 8505C cells $(P<0.0001 ; P<0.0001)$. This trend was consistent in C643 $(P=0.0009 ; P=0.0034)$ and HTH7 $(P=0.0024$; $P=0.0082$ ) cells as well (Fig. 5A). These data suggested that combination treatment-mediated cell death in ATC cells involves the collapse of MMP.

\section{Treatment with MADD siRNA and TRAIL enhances oxidative stress}

ROS generation/oxidative stress can trigger cell apoptosis by activating both mitochondrial and ER stress pathways, which can add on to TRAIL cytotoxicity. Our ROS-sensitive dye, DCFDA staining-based microscopy and quantification demonstrated that MADD depleted cells had significantly higher ROS generation as compared to vehicle control and scramble siRNA-transfected $8505 \mathrm{C}$ cells $(P=0.0343$; $P=0.024)$, C643 cells $(P=0.0135 ; P=0.0201)$ and HTH7 cells $(P=0.0056 ; P=0.0043)$. Further, TRAIL treatment induced a significant amount of ROS generation in MADD siRNA-transfected cells as compared to vehicle control and scramble siRNA-transfected $8505 \mathrm{C}$ cells $(P=0.0015$; $P=0.0028)$, C643 cells $(P=0.0033 ; P=0.0018)$ and HTH7 cells $(P=0.00012 ; P=0.00011)$ (Fig. 5B; Supplementary Fig. S2). Overall, these results imply that the combination treatment can lead to increased cellular oxidative stress that can further contribute to cell death.

\section{MADD siRNA restores TRAIL sensitivity and significantly abolishes tumor growth}

To validate the anti-tumor effects of MADD siRNA and TRAIL treatment, we created an orthotopic ATC model in athymic nude mice. Interestingly, mice treated with either MADD siRNA alone or with MADD siRNA+TRAIL exhibited rapid and significant anti-tumor responses as per WHO and RECIST criteria, in comparison to the control mice which approached humane endpoints and had to be killed. Mice treated with MADD siRNA
C) 2019 Society for Endocrinology Published by Bioscientifica Ltd. Printed in Great Britain 

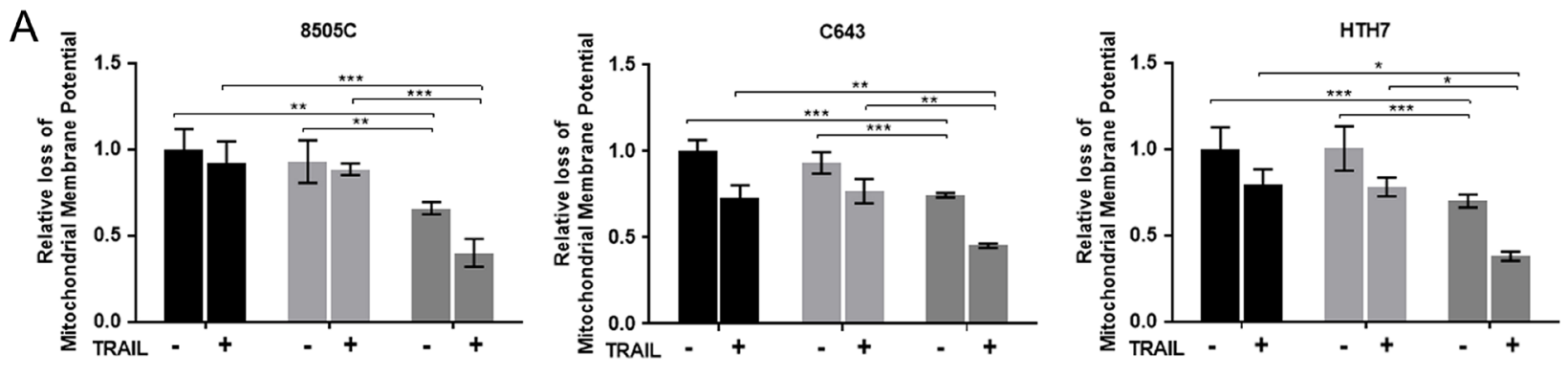

Vehicle Control $\square$ Scramble siRNA $\square$ MADD siRNA

B

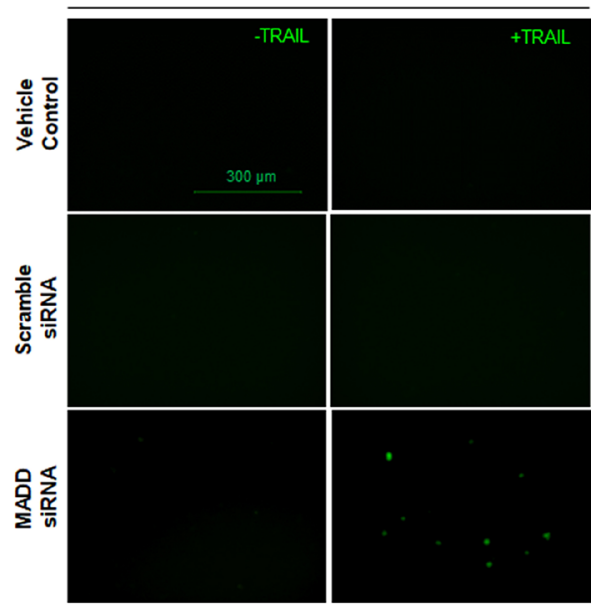

C643

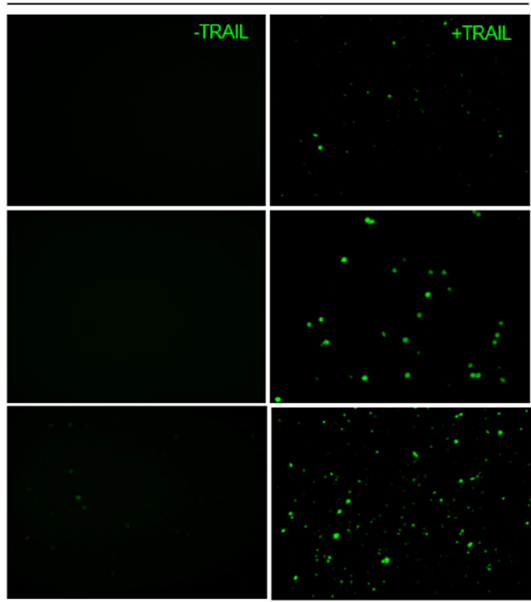

HTH7

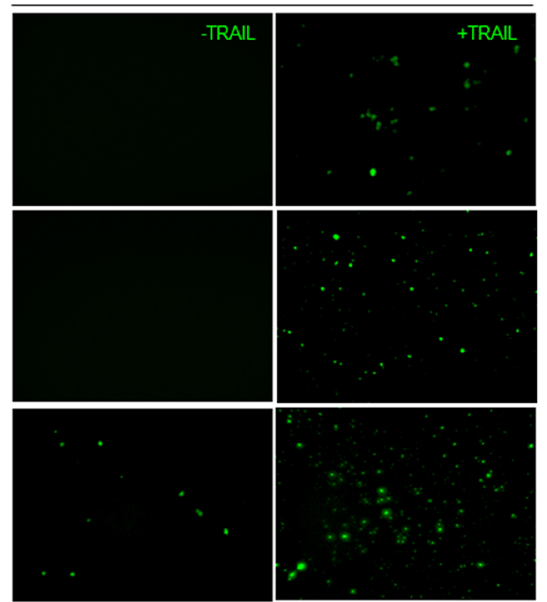

\section{Figure 5}

Effect of combination treatment on mitochondrial membrane potential and reactive oxygen species (ROS) generation: (A) Loss of mitochondrial membrane potential was assessed by determining JC-1 dye aggregates (red)/monomers (green) ratio. Relative loss of mitochondrial membrane potential of the vehicle, scramble siRNA or MADD siRNA- transfected cells, with and without TRAIL treatment is shown in the bar graphs. (B) ROS-sensitive dye, DCFDA-stained cells emitting green fluorescence, are showing accumulation of reactive oxygen species (ROS) in cells. Images were captured at 20× objective (magnification, 200 $\times$ ) using a Keyence microscope. Data are represented as a mean \pm standard deviation. Significance is represented as $*(P<0.05), * \star(P<0.005), \star \star \star(P<0.0005)$.

showed significantly reduced tumor growth relative to mice treated with saline $(P<0.0001)$, scramble siRNA $(P=0.0054)$, saline+TRAIL $(P=0.0004)$ and scramble siRNA+TRAIL $(P=0.0040)$. Treatment with MADD siRNA and TRAIL not only restored TRAIL sensitivity but also showed significantly improved anti-tumor activity than saline+TRAIL $(P<0.0001)$ and scramble siRNA+TRAIL $(P=0.0004)$-treated mice. Interestingly, we observed a significant difference in tumor growth between groups treated with MADD siRNA alone and in combination with TRAIL $(P=0.0082)$ (Fig. 6A and B; Supplementary Fig. S3A). These data clearly demonstrated the therapeutic efficacy of combining MADD siRNA and TRAIL.

\section{Combination treatment enhances apoptosis in tumor cells}

To determine whether the tumor regression was due to apoptosis, we stained the tumor tissues with antibodies specific to active caspase- 8 and active caspase-9. Our immunohistochemical studies showed that treatment with MADD siRNA alone or in combination with TRAIL resulted in activation of both, caspase- 8 and caspase- 9 relative to other treatment groups (Fig. 6C).

Quantitative analysis of active caspase- 8 staining revealed that MADD siRNA $(51.77 \pm 10.94 \%)$-treated tumors, had a significantly higher number of active caspase-8-positive cells, as compared to saline $(12.16 \pm 5.721 \%)$ and scramble siRNA (19.6 $\pm 5.023 \%)$ $(P<0.0001 ; \quad P=0.0003)$-treated tumors (Supplementary Fig. S3B). A similar trend was observed for caspase 9 staining in MADD siRNA (51.92 $\pm 9.856 \%$ )-treated tumors versus saline $(12.28 \pm 4.462 \%)$ and scramble siRNA (20.72 \pm 4.197$)$-treated tumors $(P<0.0001 ; P=0.002)$.

Comparison of caspase- 8 staining in combination treatment (MADD siRNA+TRAIL, 66.36 $\pm 5.541 \%$ ) compared to saline+TRAIL $(16.61 \pm 4.755 \%)$ and scramble siRNA+TRAIL $(16.06 \pm 6.078 \%)$ revealed a statistically 
A

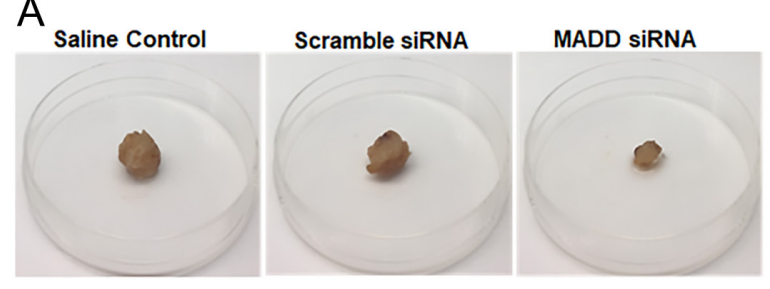

Saline + TRAIL Scramble siRNA + TRAIL MADD siRNA + TRAIL
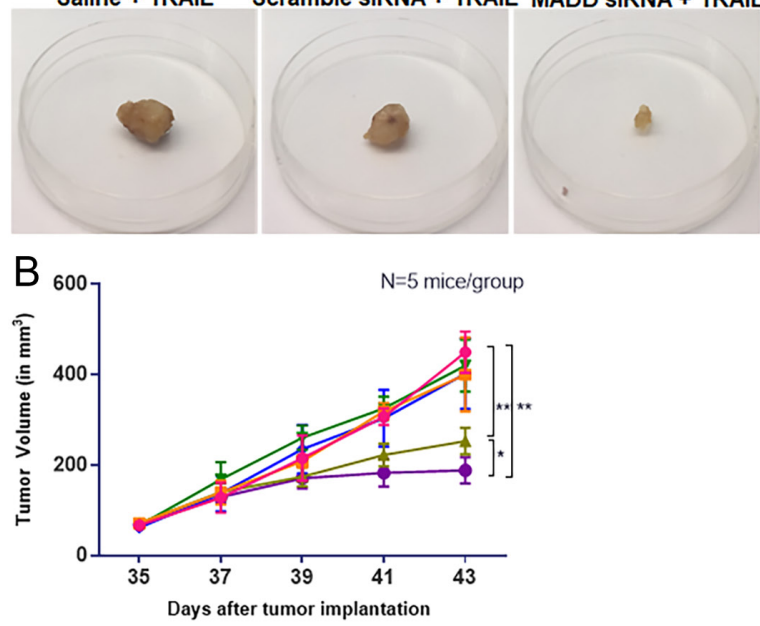

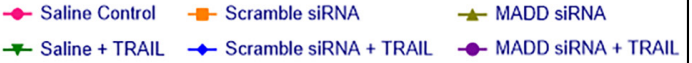

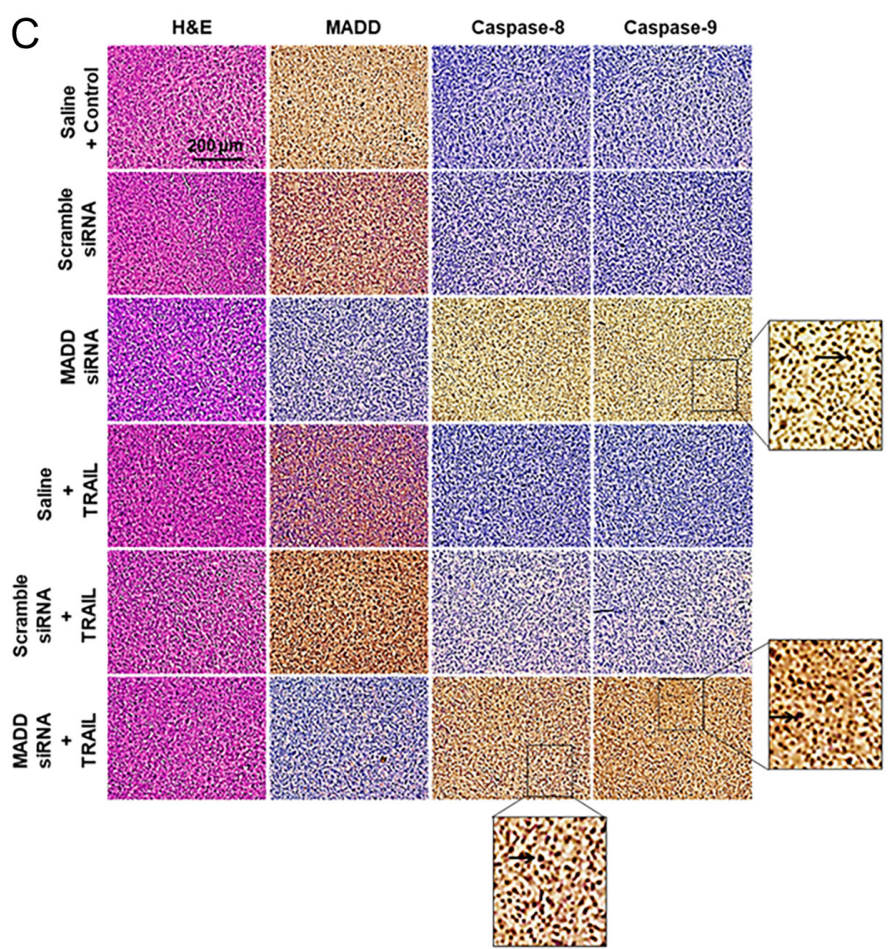

\section{Figure 6}

Tumor regression in the athymic nude mice bearing orthotopic xenografts and immunochemistry: $(A)$ representative photographs showing resected tumors from each treatment arm. (B) Tumor growth curve demonstrating the efficacy of MADD siRNA and combination treatment in vivo. In contrast, tumors treated with saline, scramble siRNA, TRAIL, scramble siRNA + TRAIL exhibited an aggressive tumor growth. Doses were administered on day 34, 36, 38, 40 and 42. (C) Representative sections from each mice group showing tissue architecture (H\&E staining), MADD expression, active caspase 8 and active caspase- 9 expression. Treatment with MADD siRNA and combination treatment resulted in activation of caspase -8 and 9, as shown above. Positive immunoreactivity was shown in brown color (diaminobenzidine-based colorimetric staining). Nuclei are shown in blue (hematoxylin). From left to right, Panel 1: H\&E staining; Panel 2: MADD expression; Panel 3: active caspase-8 expression; Panel 4: active caspase-9 expression. (Magnification 200×, Brightfield channel). Inset enlargement is $2.5 \times$ to show apoptotic cells (dark brown staining indicated by arrows).

significant difference $(P<0.001 ; P<0.001)$. Similarly, when compared to saline+TRAIL $(16.17 \pm 6.755 \%)$ and scramble siRNA and TRAIL (17.99 $\pm 7.379 \%)$-treated groups, mice treated with MADD siRNA and TRAIL (64.04 $\pm 6.979 \%)$ had significantly higher caspase-9 expression $(P<0.001$; $P<0.001$ ) (Supplementary Fig. S3B). These results confirmed the activation of both extrinsic and intrinsic apoptotic pathways in tumors treated with MADD siRNA and TRAIL.

\section{Discussion}

ATC remains largely incurable despite multimodality therapy (Kunstman et al. 2015). Drugs used in ATC treatment are either genotoxic compounds or multi-kinase inhibitors, which have limited efficacy and significant systemic toxicity. The paucity of validated cancer-specific molecular targets has hampered the development of more effective and novel therapies for ATC. Our findings using both in vitro and in vivo models have shown promising results on how a combination of MADD siRNA and TRAIL treatment might be of potential benefit in the treatment of ATC.

TRAIL is a potent apoptosis inducer, which can kill predominantly cancer cells (Lemke et al. 2014, Von Karstedt et al. 2017). Therefore, it has been considered a promising therapeutic agent and is under evaluation in clinical trials for several cancers. However, development of resistance to TRAIL has impaired its clinical utility. A fully human agonistic monoclonal antibody to TRAIL-R1, mapatumumab, showed optimal safety in phase $1 \mathrm{~b} / 2$ trial in patients with relapsed non-Hodgkin's lymphoma (NHL) (Younes et al. 2010). Other TRAIL-based therapies involving small-molecule inhibitors or agonists such as ABBV-621 (Clinical trial \# NCT03082209), DS8-273 (Clinical trial \# NCT02076451) and ONC201 (Clinical trial \# NCT02324621) have been tested in clinical trials 
on various solid tumors (Lim et al. 2015, Yuan et al. 2018). However, these regimens ran into hurdles largely because of either inherited or acquired TRAIL resistance. To increase TRAIL sensitivity, several approaches have been clinically tested. One of the proteasome inhibitors, bortezomib, has demonstrated enhanced cancer cell susceptibility to TRAIL or its agonists in several malignancies including renal cell carcinoma, leukemia, lymphomas, prostate, colon, bladder, thyroid, ovarian, lung, sarcoma, hepatoma and glioma (Brooks et al. 2010). A phase II clinical trial was conducted using mapatumumab in combination with bortezomib (Velcade) and bortezomib alone in patients with relapsed or refractory multiple myeloma (Clinical trial \# NCT00315757), but the results have not yet been published.

In this context, autophagic flux is also known to be responsible for TRAIL resistance as it regulates caspase- 8 activation and complementing TRAIL with autophagic inhibitors might be a rational approach to overcome TRAIL resistance (Fang et al. 2007, Singh et al. 2014, Trivedi \& Mishra 2015, Ryu et al. 2018, Sharma \& Almasan 2018, Nazim et al. 2019). However, further studies are needed to develop appropriate therapeutic approaches that can overcome autophagy-mediated TRAIL resistance.

MADD is a pro-survival factor (Al-Zoubi et al. 2001, Efimova et al. 2004, Ramaswamy et al. 2004, Mulherkar et al. 2006, Prabhakar et al. 2008, Subramanian et al. 2009, Li et al. 2010, 2011, 2013, Turner et al. 2013, Carr et al. 2016) that can also confer resistance to apoptosis upon Akt-mediated phosphorylation (Li et al. 2010). Thus, combining MADD siRNA with TRAIL was conceived as a promising apoptosis-enhancing strategy.

For the first time, we investigated the efficacy of TRAIL combined with MADD knockdown in a preclinical orthotopic mouse xenograft ATC model. Our studies showed that MADD siRNA could induce cell ATC cell death in a dose-dependent manner. The current siRNAbased therapy landscape includes clinical trials in solid malignancies, such as CALAA-01 targeting RRM1 and ALN-VSP02 targeting KSP and VEGF (Chen et al. 2018). Although a lack of appropriate delivery system to target specific cells remains a challenge, advances using nanoparticles, magnetic particles and folate receptorbased systems hold promise (Chen et al. 2018).

Our subsequent experiments were aimed at evaluating whether MADD siRNA and TRAIL co-treatment could be more beneficial than either treatment alone. Our data clearly showed that treatment with MADD siRNA significantly enhanced TRAIL sensitivity in 8505C, C643 and HTH7 cells. Further data analysis using the
Chou-Talalay method (Compusyn) demonstrated a synergistic effect with combination treatment in TRAIL-resistant cells. Our results clearly showed that a combination treatment with MADD siRNA and TRAIL could provide a clinically relevant strategy for overcoming TRAIL resistance and the potential utility of such an approach to treat ATC.

MADD acts as a TRAIL resistance factor by preventing caspase activation and ROS-mediated stress response (Ramaswamy et al. 2004, Mulherkar et al. 2007, Prabhakar et al. 2008, Carr et al. 2011, Li et al. 2011). For efficient TRAIL-mediated killing, caspase- 8 activation is required as it can initiate both extrinsic and intrinsic apoptotic pathways (Trivedi \& Mishra 2015). In cells with lower levels of caspase-8, mitochondria-mediated apoptotic stimulation and/or other stress-mediated responses contribute to cell death. In this context, mitochondrial depolarization (induced by KATP channel inhibitors) has been shown to support TRAIL-induced apoptosis by initiating ER stress-mediated death pathway in human melanoma cells (Suzuki et al. 2012). Increased ROS is known to potentiate TRAIL-mediated cytotoxicity mainly via ROS-mediated upregulation of DR5 expression (Mellier \& Pervaiz 2012). ROS-induced oxidative stress can cause accumulation of unfolded proteins leading to ER stress and apoptosis mediated through ER-associated apoptotic proteins. Consistent with this, a positive feedback loop between mitochondrial depolarization and ROS generation (Suzuki-Karasaki et al. 2014) has been described. Similarly, we observed that combination treatment also resulted in the collapse of MMP and accumulation of ROS. Similar to our findings, one of the TRAIL-sensitizing agents, sorafenib (multi-kinase inhibitor) has been shown to overcome inherent TRAIL resistance by rapid dissipation of MMP and ROS accumulation in renal cell carcinoma (Gillissen et al. 2017). In conclusion, combination treatment with MADD siRNA and TRAIL can combat TRAIL resistance by promoting several pro-apoptotic responses. Further studies are warranted to fully understand the relative contributions of different apoptotic signals.

Our in vivo studies in athymic nude mice bearing orthotopic TRAIL-resistant ATC tumors showed that MADD siRNA treatment could cause significant tumor growth suppression relative to those treated with saline or scramble siRNA. Combination treatment not only restored TRAIL sensitivity but also resulted in greater tumor regression than TRAIL or MADD siRNA alone. (Fig. 6). Immunohistochemical studies confirmed that combination treatment-induced tumor growth reduction (c) 2019 Society for Endocrinology Published by Bioscientifica Ltd. Printed in Great Britain 
was associated with the activation of caspase- 8 and caspase-9, effectors of apoptosis.

In summary, MADD siRNA can not only cause apoptosis on its own but can also sensitize ATC to TRAIL treatment. Although the clinical feasibility is yet to be established, our results show the potential utility of MADD siRNA therapy for ATC either alone or in combination with TRAIL.

\section{Supplementary data}

This is linked to the online version of the paper at https://doi.org/10.1530/ ERC-18-0517.

\section{Declaration of interest}

The authors declare that there is no conflict of interest that could be perceived as prejudicing the impartiality of the research reported.

\section{Funding}

This study was supported by the VA grant (project \# 1I01BX002285-01A1) to Dr Prabhakar.

\section{References}

Al-Zoubi AM, Efimova EV, Kaithamana S, Martinez O, El-Idrissi Mel-A, Dogan RE \& Prabhakar BS 2001 Contrasting effects of IG20 and its splice isoforms, MADD and DENN-SV, on tumor necrosis factor $\alpha$-induced Apoptosis and Activation of caspase-8 and -3. Journal of Biological Chemistry 276 47202-47211. (https://doi.org/10.1074/jbc. M104835200)

Brooks AD, Jacobsen KM, Li W, Shanker A \& Sayers TJ 2010 Bortezomib sensitizes human renal cell carcinomas to TRAIL apoptosis via increased activation of caspase-8 in the death-inducing signaling complex. Molecular Cancer Research: MCR 8 729-738. (https://doi. org/10.1158/1541-7786.MCR-10-0022)

Carr RM, Pilli T, Li L, Prabhakar B \& Maker AV 2011 Inhibition of the pro-survival factor MADD (MAP kinase Activating Death Domain) in human colorectal cancer. Journal of the American College of Surgeons 213 (Supplement) S132-S133. (https://doi.org/10.1016/j. jamcollsurg.2011.06.319)

Carr RM, Qiao G, Qin J, Jayaraman S, Prabhakar BS \& Maker AV 2016 Targeting the metabolic pathway of human colon cancer overcomes resistance to TRAIL-induced apoptosis. Cell Death Discovery 216067. (https://doi.org/10.1038/cddiscovery.2016.67)

Chen X, Mangala LS, Rodriguez-Aguayo C, Kong X, Lopez-Berestein G \& Sood AK 2018 RNA interference-based therapy and its delivery systems. Cancer Metastasis Reviews 37 107-124. (https://doi. org/10.1007/s10555-017-9717-6)

Chou TC 2010 Drug combination studies and their synergy quantification using the Chou-Talalay method. Cancer Research $\mathbf{7 0}$ 440-446. (https://doi.org/10.1158/0008-5472.CAN-09-1947)

Efimova EV, Al-Zoubi AM, Martinez O, Kaithamana S, Lu S, Arima T \& Prabhakar BS 2004 IG20, in contrast to DENN-SV, (MADD splice variants) suppresses tumor cell survival, and enhances their susceptibility to apoptosis and cancer drugs. Oncogene 23 1076-1087. (https://doi.org/10.1038/sj.onc.1207210)

(c) 2019 Society for Endocrinology Published by Bioscientifica Ltd. Printed in Great Britain
Fang D, Hawke D, Zheng Y, Xia Y, Meisenhelder J, Nika H, Mills GB, Kobayashi R, Hunter T \& Lu Z 2007 Phosphorylation of $\beta$-catenin by AKT promotes $\beta$-catenin transcriptional activity. Journal of Biological Chemistry 282 11221-11229. (https://doi.org/10.1074/jbc. M611871200)

Gillissen B, Richter A, Richter A, Preissner R, Schulze-Osthoff K, Essmann F \& Daniel PT 2017 Bax/Bak-independent mitochondrial depolarization and reactive oxygen species induction by sorafenib overcome resistance to apoptosis in renal cell carcinoma. Journal of Biological Chemistry 292 6478-6492. (https://doi.org/10.1074/jbc. M116.754184)

Jung EM, Lim JH, Lee TJ, Park JW, Choi KS \& Kwon TK 2005 Curcumin sensitizes tumor necrosis factor-related apoptosis-inducing ligand (TRAIL)-induced apoptosis through reactive oxygen species-mediated upregulation of death receptor 5 (DR5). Carcinogenesis 26 1905-1913. (https://doi.org/10.1093/carcin/bgi167)

Kunstman JW, Juhlin CC, Goh G, Brown TC, Stenman A, Healy JM, Rubinstein JC, Choi M, Kiss N, Nelson-Williams C, et al. 2015 Characterization of the mutational landscape of anaplastic thyroid cancer via whole-exome sequencing. Human Molecular Genetics $\mathbf{2 4}$ 2318-2329. (https://doi.org/10.1093/hmg/ddu749)

Kurada BR, Li LC, Mulherkar N, Subramanian M, Prasad KV \& Prabhakar BS 2009 MADD, a splice variant of IG20, is indispensable for MAPK activation and protection against apoptosis upon tumor necrosis factor- $\alpha$ treatment. Journal of Biological Chemistry $\mathbf{2 8 4}$ 13533-13541. (https://doi.org/10.1074/jbc.M808554200)

Lemke J, Von Karstedt S, Zinngrebe J \& Walczak H 2014 Getting TRAIL back on track for cancer therapy. Cell Death and Differentiation 21 1350-1364. (https://doi.org/10.1038/cdd.2014.81)

Li P, Jayarama S, Ganesh L, Mordi D, Carr R, Kanteti P, Hay N \& Prabhakar BS 2010 Akt-phosphorylated mitogen-activated kinaseactivating Death Domain Protein (MADD) inhibits TRAIL-induced apoptosis by blocking Fas-associated death domain (FADD) association with death receptor 4 Fas. Journal of Biological Chemistry 285 22713-22722. (https://doi.org/10.1074/jbc.M110.105692)

Li LC, Jayaram S, Ganesh L, Qian L, Rotmensch J, Maker AV \& Prabhakar BS 2011 Knockdown of MADD and c-FLIP overcomes resistance to TRAIL-induced apoptosis in ovarian cancer cells. American Journal of Obstetrics and Gynecology 205 362.e12-362.e25. (https://doi.org/10.1016/j.ajog.2011.05.035)

Li LC, Jayarama S, Pilli T, Qian L, Pacini F \& Prabhakar BS 2013 Downmodulation of expression, or dephosphorylation, of IG20/MADD in tumor necrosis factor-related apoptosis-inducing ligand-resistant thyroid cancer cells makes them susceptible to treatment with this ligand. Thyroid 23 70-78. (https://doi.org/10.1089/thy.2012.0155)

Lim B, Allen JE, Prabhu VV, Talekar MK, Finnberg NK \& El-Deiry WS 2015 Targeting TRAIL in the treatment of cancer: new developments. Expert Opinion on Therapeutic Targets 19 1171-1185. (https://doi.org/1 $0.1517 / 14728222.2015 .1049838)$

Luszczki JJ, Borowicz KK, Swiader M \& Czuczwar SJ 2003 Interactions Between oxcarbazepine and conventional antiepileptic drugs in the maximal electroshock test in mice: an isobolographic analysis. Epilepsia 44 489-499. (https://doi. org/10.1046/j.1528-1157.2003.32702.x)

Mahalingam D, Szegezdi E, Keane M, De Jong S \& Samali A 2009 TRAIL receptor signalling and modulation: are we on the right TRAIL? Cancer Treatment Reviews 35 280-288. (https://doi.org/10.1016/j. ctrv.2008.11.006)

Mellier G \& Pervaiz S 2012 The three Rs along the TRAIL: resistance, re-sensitization and reactive oxygen species (ROS). Free Radical Research 46 996-1003. (https://doi.org/10.3109/10715762. 2012.690514)

Mulherkar N, Ramaswamy M, Mordi DC \& Prabhakar BS 2006 MADD/ DENN splice variant of the IG20 gene is necessary and sufficient for cancer cell survival. Oncogene 25 6252-6261. (https://doi. org/10.1038/sj.onc.1209650) 
Mulherkar N, Prasad KV \& Prabhakar BS 2007 MADD/DENN splice variant of the IG20 gene is a negative regulator of caspase-8 activation: knockdown enhances TRAIL-induced apoptosis of cancer cells. Journal of Biological Chemistry 282 11715-11721. (https://doi. org/10.1074/jbc.M701085200)

Nazim UM, Yin H \& Park SY 2019 Autophagy flux inhibition mediated by celastrol sensitized lung cancer cells to TRAILinduced apoptosis via regulation of mitochondrial transmembrane potential and reactive oxygen species. Molecular Medicine Reports 19 984-993. (https://doi.org/10.3892/mmr.2018.9757)

Prabhakar BS, Mulherkar N \& Prasad KV 2008 Role of IG20 splice variants in TRAIL resistance. Clinical Cancer Research 14 347-351. (https://doi.org/10.1158/1078-0432.CCR-07-0493)

Purdy AK, Alvarez Arias DA, Oshinsky J, James AM, Serebriiskii I \& Campbell KS 2014 The AP-2 clathrin adaptor mediates endocytosis of an inhibitory killer cell Ig-like receptor in human NK cells. Journal of Immunology 193 4675-4683. (https://doi.org/10.4049/ jimmunol.1303406)

Qiao G, Qin J, Kunda N, Calata JF, Mahmud DL, Gann PH, Fu YX, Rosenberg SA, Prabhakar BS \& Maker AV 2017 LIGHT elevation enhances immune eradication of colon cancer metastases. Cancer Research 77 1880-1891. (https://doi.org/10.1158/0008-5472. CAN-16-1655)

Ramaswamy M, Efimova EV, Martinez O, Mulherkar NU, Singh SP \& Prabhakar BS 2004 IG20 (MADD splice variant-5), a proapoptotic protein, interacts with DR4/DR5 and enhances TRAIL-induced apoptosis by increasing recruitment of FADD and caspase- 8 to the DISC. Oncogene 23 6083-6094. (https://doi.org/10.1038/sj. onc.1207804)

Roche AM, Fedewa SA, Shi LL \& Chen AY 2018 Treatment and survival vary by race/ethnicity in patients with anaplastic thyroid cancer. Cancer 124 1780-1790. (https://doi.org/10.1002/cncr.31252)

Ryu S, Ahn YJ, Yoon C, Chang JH, Park Y, Kim TH, Howland AR, Armstrong CA, Song PI \& Moon AR 2018 The regulation of combined treatment-induced cell death with recombinant TRAIL and bortezomib through TRAIL signaling in TRAIL-resistant cells. BMC Cancer 18 432. (https://doi.org/10.1186/s12885-018-4352-3)

Saini S, Jagadish N, Gupta A, Bhatnagar A \& Suri A 2013 A novel cancer testis antigen, A-kinase anchor protein 4 (AKAP4) is a potential biomarker for breast cancer. PLoS One $\mathbf{8}$ e57095. (https://doi. org/10.1371/journal.pone.0057095)

Sharma A \& Almasan A 2018 Autophagy as a mechanism of Apo2L/ TRAIL resistance. Cancer Biology and Therapy 19 755-762. (https:// doi.org/10.1080/15384047.2018.1472191)
Shirley S, Morizot A \& Micheau O 2011 Regulating TRAIL receptorinduced cell death at the membrane: a deadly discussion. Recent Patents on Anti-Cancer Drug Discovery 6 311-323. (https://doi. org/10.2174/157489211796957757)

Singh K, Sharma A, Mir MC, Drazba JA, Heston WD, Magi-Galluzzi C, Hansel D, Rubin BP, Klein EA \& Almasan A 2014 Autophagic flux determines cell death and survival in response to Apo2L/TRAIL (dulanermin). Molecular Cancer 13 70. (https://doi.org/10.1186/14764598-13-70)

Subramanian M, Pilli T, Bhattacharya P, Pacini F, Nikiforov YE, Kanteti PV \& Prabhakar BS 2009 Knockdown of IG20 gene expression renders thyroid cancer cells susceptible to apoptosis. Journal of Clinical Endocrinology and Metabolism 94 1467-1471. (https://doi.org/10.1210/jc.2008-2378)

Suzuki Y, Inoue T, Murai M, Suzuki-Karasaki M, Ochiai T \& Ra C 2012 Depolarization potentiates TRAIL-induced apoptosis in human melanoma cells: role for ATP-sensitive $\mathrm{K}+$ channels and endoplasmic reticulum stress. International Journal of Oncology $\mathbf{4 1} 465-475$. (https://doi.org/10.3892/ijo.2012.1483)

Suzuki-Karasaki M, Ochiai T \& Suzuki-Karasaki Y 2014 Crosstalk between mitochondrial ROS and depolarization in the potentiation of TRAIL-induced apoptosis in human tumor cells. International Journal of Oncology $\mathbf{4 4}$ 616-628. (https://doi.org/10.3892/ ijo.2013.2215)

Trivedi R \& Mishra DP 2015 Trailing TRAIL resistance: novel targets for TRAIL sensitization in cancer cells. Frontiers in Oncology 569. (https://doi.org/10.3389/fonc.2015.00069)

Turner A, Li LC, Pilli T, Qian L, Wiley EL, Setty S, Christov K, Ganesh L, Maker AV, Li P, et al. 2013 MADD knock-down enhances doxorubicin and TRAIL induced apoptosis in breast cancer cells. PLoS One 8 e56817. (https://doi.org/10.1371/journal. pone.0056817)

Von Karstedt S, Montinaro A \& Walczak H 2017 Exploring the TRAILs less travelled: TRAIL in cancer biology and therapy. Nature Reviews: Cancer 17 352-366. (https://doi.org/10.1038/nrc.2017.28)

Younes A, Vose JM, Zelenetz AD, Smith MR, Burris HA, Ansell SM, Klein J, Halpern W, Miceli R, Kumm E, et al. 2010 A phase 1b/2 trial of mapatumumab in patients with relapsed/refractory non-Hodgkin's lymphoma. British Journal of Cancer 103 1783-1787. (https://doi. org/10.1038/sj.bjc.6605987)

Yuan X, Gajan A, Chu Q, Xiong H, Wu K \& Wu GS 2018 Developing TRAIL/TRAIL death receptor-based cancer therapies. Cancer Metastasis Reviews 37 733-748. (https://doi.org/10.1007/ s10555-018-9728-y)

Received in final form 14 February 2019 Accepted 25 March 2019 (c) 2019 Society for Endocrinology Published by Bioscientifica Ltd. Printed in Great Britain 